\title{
Benign Cervical Mixed Epithelial and Mesenchymal Neoplasm
}

National Cancer Institute

\section{Source}

National Cancer Institute. Benign Cervical Mixed Epithelial and Mesenchymal Neoplasm. NCl Thesaurus. Code C40227.

A neoplasm that arises from the cervix and is characterized by the presence of benign epithelial and benign mesenchymal elements. This category includes adenofibroma and adenomyoma. 